\title{
Mecanismos jurídicos de protección internacional frente a la violencia sexual y basada en el género en América Latina
}

\author{
José Díaz Lafuente \\ Universitat Jaume I
}

\section{Resumen}

De acuerdo con recientes informes publicados por la Organización de las Naciones Unidas, América Latina constituye la región que presenta los mayores índices de violencia sexual y basada en el género perpetrada contra las mujeres y contra todas aquellas personas cuya identidad de género u orientación sexual no se ajustan a los parámetros tradicionales y heteronormativos del patriarcado.

Partiendo de un contexto global marcado por los desplazamientos migratorios masivos y por los alarmantes índices de VSBG, en el presente artículo, desde un enfoque integral y tomando en consideración la interseccionalidad que la cuestión requiere, se introduce un análisis crítico de los mecanismos jurídicos de protección del sistema internacional de derechos humanos para proceder, a continuación, desde la perspectiva de género, al estudio del marco normativo regulador de la política de asilo de la Unión Europea.

Todo ello, con el objetivo principal de subrayar las garantías necesarias para el reconocimiento efectivo e igualitario del derecho a solicitar protección internacional por parte de aquellas mujeres y personas LGBT+ perseguidas, reconociendo, al mismo tiempo, el androcentrismo predominante en la política de asilo de la UE e identificando aquellas buenas prácticas potencialmente extrapolables a otras jurisdicciones latinoamericanas.

Palabras clave: Protección internacional, Género, Violencia sexual .

\section{Legal mechanisms of international protection in the light of the rates of sexual and gender-based violence in Latin America}

\begin{abstract}
According to recent reports published by the United Nations, Latin America is the region with the highest rates of sexual and gender-based violence perpetrated against women and against all those whose gender identity or sexual orientation does not fit to the traditional and heteronormative parameters of patriarchy.

On the basis of the global context affected by massive migratory movements and by alarming rates of VSBG, in this paper, from an integral approach and taking into consideration the intersectionality that the issue requires, it is introduced a critical analysis of the legal protection mechanisms of the international human rights system to proceed, from a gender perspective, to the study of the normative regulatory framework of the European Union asylum policy. All this, with the aim of highlighting the necessary guarantees for the effective and equal recognition of the right to request international protection by persecuted women and LGBT+ people, recognizing the predominant androcentrism existing in the EU asylum policy and identifying those good practices that can be extrapolated to other Latin American jurisdictions.
\end{abstract}

Keywords: International protection, Gender, Sexual violence .

\footnotetext{
*Dirección de correspondencia [Correspondence address]:

José Díaz Lafuente, Universitat Jaume I

E-mail: jlafuent@uji.es
} 


\section{La violencia sexual y basada en el género a nivel interna- cional y en América Latina}

La violencia sexual y basada en el género (VSBG) se presenta como uno de los principales desafíos a los que se enfrenta la comunidad internacional en su conjunto para la consecución de un pleno y efectivo reconocimiento de los derechos humanos.

Mientras el artículo $1^{\underline{0}}$ de la Declaración Universal de los Derechos Humanos, adoptada por la Asamblea General de las Naciones Unidas en 1948, dispone que "todos los seres humanos nacemos libres e iguales en dignidad y derechos", la Organización Mundial de la Salud estima que, en la actualidad, en el septuagésimo aniversario de la citada declaración, el 35 por ciento de las mujeres de todo el mundo han sufrido o sufrirán violencia física y/o sexual en algún momento de su vida (Organización Mundial de la Salud, 2013: 1) $)^{1}$.

La VSBG incluye toda una serie de violaciones de derechos humanos que tiene como víctimas a las mujeres y a aquellas personas cuya identidad de género u orientación sexual no se conciben como normativizadas, al no ajustarse a los parámetros tradicionales del patriarcado, la derivada configuración jerárquica y binaria del género y la consecuente conformación heteronormativa de las relaciones afectivo-sexuales.

Conviene recordar, además, que muchas mujeres y personas LGBT + huyen de sus países de origen por conflictos bélicos, inestabilidad en la región y por violaciones de sus derechos humanos, todos ellas situaciones inclusivas de una violencia de género estructural presente en todas las regiones del mundo. La violencia contra la mujer y las personas LGBT+ abarca todo un conjunto de abusos y violaciones derechos humanos, en demasiadas ocasiones justificados, e incluso reconocidos y promovidos a nivel institucional, bajo los claroscuros del relativismo cultural que defiende unos valores sociales, religiosos, económicos y políticos que determinan por el género de la persona qué funciones se esperan de la mujer y el hombre, la relación entre estos roles sociales y el estatus social

\footnotetext{
${ }^{1}$ Debe destacarse que, de acuerdo con el citado informe, aquellas mujeres víctimas de maltrato físico o sexual por parte de sus compañeros tienen "más del doble de posibilidades de tener un aborto, casi el doble de posibilidades de sufrir depresión y, en algunas regiones, 1,5 veces más posibilidades de contraer el VIH, en comparación con las mujeres que no han sufrido violencia por parte de su compañero sentimental" (Organización Mundial de la Salud, 2013: 2)
}

derivado de los mismos ${ }^{2}$.

En esta línea, la consideración de las mujeres y de las personas LGBT+ como ciudadanas y ciudadanos de segunda es clave para comprender la existencia de unos índices alarmantes de abusos y vulneraciones de derechos fundamentales que "trascienden los límites entre lo público y lo privado, así como las fronteras entre los estados-nación: asesinatos, agresiones, esclavitud sexual y torturas, que suceden en el hogar, en la calle y en el lugar de trabajo; como un arma de guerra, de dictaduras, de limpiezas étnicas y discriminaciones crónicas; y contra migrantes, desplazados internos y residentes en espacios ingobernados" (Brysk, 2017: 9).

De acuerdo con la definición de la VSBG utilizada por el ACNUR y sus Agencias Ejecutoras Asociadas ${ }^{3}$, se concibe como aquella violencia que es perpetrada por el género de la víctima a quien se le causa, o se le amenaza con, un daño o sufrimiento físico, mental o sexual que abarca:

1. La violencia física, sexual y psicológica que se produzca en la familia, incluidos los malos tratos, la explotación sexual, el abuso sexual de menores en el hogar, violencia relacionada con la dote, violación por el marido, la mutilación genital femenina y otras prácticas tradicionales dañinas para la mujer, los actos de violencia perpetrados por otros miembros de la familia y la violencia relacionada con la explotación.

2. La violencia física, sexual y psicológica perpetrada dentro de la comunidad en general, inclusive la violación, el abuso sexual, el acoso y la intimidación sexuales en el trabajo, en instituciones educacionales y en otros lugares, la trata de mujeres y la prostitución forzada.

3. La violencia física, sexual y psicológica

\footnotetext{
${ }^{2}$ En relación con el debate sobre el universalismo de los derechos humanos frente a la posibilidad de limitarlos en función de las particularidades culturales o religiosas de cada Estado o región, conviene hacer mención a la Declaración y el Programa de Acción de Viena de la Conferencia Mundial de Derechos Humanos de 1993 que, en su apartado $5^{\mathrm{a}}$, confirmaron que, aunque "debe tenerse en cuenta la importancia de las particularidades nacionales y regionales, así como de los diversos patrimonios históricos, culturales y religiosos, los Estados tienen el deber, sean cuales fueren sus sistemas políticos, económicos y culturales, de promover y proteger todos los derechos humanos y las libertades fundamentales"(A/CONF.157/23, 1993: 5)

${ }^{3}$ Definición basada en los artículos 1 y 2 de la Declaración de la Asamblea General de la ONU sobre la Eliminación de la Violencia Contra la Mujer de 1993 y en la Recomendación No. 19, párrafo 6 de la sesión No. 11 del Comité Para la Eliminación de la Discriminación Contra la Mujer (CEDAW)
} 
perpetrada o tolerada por el Estado e instituciones, dondequiera que ocurra

(Alto Comisionado de las Naciones Unidas para los Refugiados, 2003: 11).

Los informes oficiales publicados por organizaciones y mecanismos internacionales y regionales cuyo mandato consiste en la promoción y protección de los derechos humanos reflejan elevados índices de VSBG, poniendo de manifiesto que nos encontramos ante una pandemia de escala global que afecta a todas las regiones del mundo. En esta línea, la Oficina de las Naciones Unidas contra la Droga y el Delito, en un informe publicado en 2014, ha estimado que la mitad de las mujeres que mueren de forma violenta en todo el mundo son asesinadas por miembros de su propia familia (Oficina de las Naciones Unidas contra la Droga y el Delito, 2014: 2).

Del mismo modo, la Organización Internacional del Trabajo (OIT) ha considerado recientemente que, de los 25 millones de personas sometidas a trabajo forzoso, tres quintos son mujeres y que más de 4,8 millones, prácticamente en su totalidad mujeres, son víctimas de trata y de explotación sexual. La OIT también ha revelado que el $88 \%$ de los 15 millones de personas que están sujetas a matrimonios forzados son mujeres (Organización Internacional del Trabajo, 2017: 11).

Por su parte, la Relatora Especial sobre la violencia contra la mujer, sus causas y consecuencias, ha subrayado que la prevalencia mundial de asesinatos de mujeres por razones de género está cobrando proporciones alarmantes, principalmente en América Latina (A/HRC/20/16, 2012: 7).

En línea con la investigación realizada por la autora López Pons (2011), América Latina es una de las regiones más afectadas por el problema del feminicidio y la violencia de género, "en donde las construcciones sociales y culturales perpetúan una sociedad patriarcal" (López Pons, 2011: 8).

Es en esta región en la que los índices de violencia por motivos de género son los más elevados. De acuerdo con la OMS, mientras que en Europa Occidental la tasa de prevalencia de la violencia en la pareja es del 19,3\%, en América Latina esta tasa es significativamente superior: 40,63\% en la región andina, 29,51\% en América Central y 23,68\% en América del Sur (Organización Mundial de la Salud, 2013: 47).

Además, en un reciente informe del PNUD de 2017, en el que se destacan datos procedentes de infor- mes regionales previos (Programa de Naciones Unidas para el Desarrollo, 2017), se subraya que "3 de los 10 países con las tasas más altas de violaciones de mujeres y niñas se encuentran en el Caribe y que la expresión más radical de esta violencia, el femicidio/feminicidio, está tomando una magnitud y ensañamiento devastador en Centroamérica, donde 2 de cada 3 mujeres asesinadas mueren por razón de su género" (Programa de Naciones Unidas para el Desarrollo, 2017: 6).

Debido a estos índices de feminicidio ${ }^{4}$, y demás formas de VSBG, tan elevados, y como respuesta a la presión interna y externa, en la segunda mitad de la década de los noventa del siglo pasado, los países de América Latina empezaron a tomar medidas contra la violencia y la discriminación contra la mujer (Saccomano, 2017: 51). En esta sentido, resulta paradójico el hecho de que, tras más de dos décadas desde la firma de la Convención Interamericana de Belém do Pará para prevenir, sancionar y erradicar la violencia contra la mujer, la región en donde persisten los mayores índices de violencia sexual y basada en el género sea, al mismo tiempo, la más avanzada en materia de legislación y políticas públicas para hacer frente a la violencia contra la mujer (Programa de Naciones Unidas para el Desarrollo, 2017: 7$)^{5}$.

A tenor de lo dispuesto, y en el marco de las políticas públicas adoptadas a nivel internacional, regional y nacional tendientes a la erradicación de las violaciones de derechos humanos por motivos de género, resulta destacable como el discurso normativo de los derechos humanos ha ido ampliando el ámbito subjetivo del derecho de asilo para reconocer la protección internacional a aquellas personas perseguidas por motivos de género.

A continuación, a la luz de los elevados índices de VSBG presentes en América Latina, se introduce un análisis crítico de los mecanismos de protección del sistema internacional de derechos humanos para ofrecer, desde la perspectiva de género, un estudio del

\footnotetext{
${ }^{4}$ En el presente trabajo se parte de un concepto de feminicidio tal como lo desarrolló Lagarde (2006) inclusivo no solo del femicidio sino también de todos aquellos tipos de violencia de género, como por ejemplo la violencia institucionalizada (Lagarde, 2006: 216)

${ }^{5}$ De acuerdo con (Programa de Naciones Unidas para el Desarrollo, 2017) "Casi todos los países cuentan con planes nacionales para la eliminación de la violencia de género, siendo 15 de ellos específicos sobre violencia contra las mujeres. El $27 \%$ de los países ha sancionado leyes "de segunda generación" o integrales, las cuales amplían las distintas manifestaciones de violencia (física, psicológica, sexual, económica o patrimonial, obstétrica, simbólica, mediática, etc.) en los ámbitos privado y público"
} 
marco normativo regulador de la política de asilo de la Unión Europea.

\section{La consideración de la YSBG en la agenda in- ternacional. Análisis de su reconocimiento en el mar- co jurídico internacional y regional de los Derechos Humanos}

La nueva Agenda de los Objetivos de Desarrollo Sostenible (ODS) y la Agenda de Desarrollo 2030, de forma pionera en el marco de las relaciones internacional, han establecido el compromiso de los Estados de la comunidad internacional para la aprobación de políticas públicas que persigan la prevención, erradicación y protección frente la violencia perpetrada contra las mujeres y las niñas como una de las prioridades a escala global. De acuerdo con el PNUD, "la reducción de la violencia contra las mujeres es un factor catalítico para la consecución de los ODS y es fundamental para el logro de la paz, la productividad económica, los derechos, la justicia y la cohesión social (objetivos 5 y 16)" (Programa de Naciones Unidas para el Desarrollo, 2017: 8).

En las últimas décadas, el sistema internacional de los derechos humanos ha establecido toda una serie de obligaciones jurídicas a los Estados cuyo núcleo se articula en la erradicación de las violaciones de derechos humanos por motivos de género.

En esta línea, y a pesar de que pueda defenderse que la cuestión de la VSBG no siempre haya sido incluida en el régimen internacional de derechos humanos original o que hayan podido sido ignorada o naturalizada por las relaciones internacionales convencionales (Brysk, 2017: 8), diversos instrumentos internacionales abordan específicamente la violencia sexual y por motivos de género en contra de mujeres y niñas, entre ellos: la Convención para la Eliminación de Todas las Formas de Discriminación Contra la Mujer, adoptada por la Asamblea General en 1979; la Declaración sobre la Eliminación de la Violencia Contra la Mujer, adoptada por la Asamblea General en 1993; y la Declaración de Beijing y la Plataforma para la Acción, adoptadas en Beijing en 1995.

Todos estos instrumentos incluyen todas las formas de discriminación como violencia contra las mujeres y las niñas y reafirman la responsabilidad de los Estados de trabajar para eliminarlas (Alto Comisionado de las Naciones Unidas para los Refugiados, 2003: 8). Además, frente a los elevados índices de feminicidios en América Latina, conviene recordar que el derecho a la vida es considerado el derecho humano supremo, en cuanto su protección y su garantía son esenciales para el ejercicio del resto de los derechos humanos.

El derecho a no ser arbitrariamente privado de la vida es un derecho universal protegido por los principales instrumentos jurídicos internacionales de derechos humanos ${ }^{6}$, así como en los tratados regionales de derechos humanos (art. $1^{\underline{0}}$ de la Declaración Americana de los Derechos y Deberes del Hombre, art. $4^{\underline{0}}$ de la Convención Americana sobre Derechos Humanos, art. $5^{\underline{0}}$ de la Carta Árabe de Derechos Humanos y art. $2^{\underline{0}}$ del Convenio Europeo de Derechos Humanos y art. $2^{\underline{O}}$ de la Carta Fundamental de Derechos de la Unión Europea).

Por su parte, el Comité de Derechos Humanos de las Naciones Unidas ha señalado que el derecho a la vida es el "derecho supremo respecto del cual no se autoriza suspensión alguna, ni siquiera en situaciones excepcionales que pongan en peligro la vida de la nación".

El derecho a la vida genera dos obligaciones principales a los Estados, conforme a lo establecido por el Derecho Internacional Público. En primer lugar, la obligación negativa de que nadie sea privado arbitrariamente de su vida, obligación absoluta de naturaleza de ius cogens que no puede ser derogada en circunstancia alguna. Y, en segundo lugar, la obligación positiva de tomar las medidas necesarias para garantizar y proteger el derecho a la vida. En este sentido, el Alto Comisionado de las Naciones Unidas para los Derechos Humanos ha establecido que: "el Estado tiene la obligación de ejercer la diligencia debida para prevenir y sancionar la privación de la vida, ofrecer reparación al respecto e investigar y enjuiciar todos los actos de violencia selectiva" (Alto Comisionado de las Naciones Unidas para los Derechos Humanos,

\footnotetext{
${ }^{6}$ En el art. 3 de la Declaración Universal de los Derechos Humanos, en el art.6 del Pacto Internacional de Derechos Civiles y Políticos; en el art.9 de la Convención Internacional sobre la protección de los derechos de todos los trabajadores migratorios y de sus familiares; en el art. 6 del Convenio de los Derechos del Niño; en el art. 10 del Convenio sobre las Personas con Discapacidad; en el Principio 1 de los Principios de la ONU relativos a una eficaz prevención e investigación de las ejecuciones extrajudiciales, arbitrarias o sumarias ; en el art. 7 de la Declaración de las Naciones Unidas sobre los derechos de los pueblos indígenas.
} 
2002: 9).

La VSBG también es contemplada por el Estatuto de Roma de 1998 de la Corte Penal Internacional que establece como crímenes contra la humanidad la violación, la esclavitud sexual, la prostitución forzada, el embarazo obligatorio, la esterilización forzada y cualquier otra forma de violencia sexual de una gravedad comparable a las anteriores.

Del mismo modo, diversas resoluciones aprobadas en el seno del Consejo de Seguridad de las Naciones Unidas abordan la cuestión de la violencia sexual y basada en el género. Destaca la Resolución 1325 (2000) que, de forma histórica y pionera, estableció la responsabilidad de los Estados para terminar con la impunidad por crímenes contra la humanidad y los crímenes de guerra, incluyendo la violencia sexual y otras formas de violencia en contra de las mujeres y niñas. En dicha resolución se "prioriza en la agenda internacional la atención a las mujeres y niñas que huyen de los conflictos armados y de contextos de violencia sistemática, instando a los Estados a ofrecer una especial atención específica a las mujeres y niñas refugiadas" 7 .

A la citada Resolución le siguieron, reconociendo elementos vinculados a la VSBG, la Resolución 1820 (2008), la Resolución 1888 (2009), la Resolución 1889 (2009), la Resolución 1960 (2010), la Resolución 2106 (2013). En materia de protección internacional de las personas desplazadas por motivos de género destaca la Resolución 1820 (2008) que insta, en su punto 10ㅜㅡ, a los organismos de las Naciones Unidas a que: "elaboren mecanismos eficaces para proteger de la violencia, en particular de la violencia sexual, a las mujeres y las niñas en los campamentos de refugiados y desplazados internos administrados por las Naciones Unidas" 8 .

Por último, conviene subrayar que la violencia sexual y por motivos de género en el contexto del asilo también ha sido reconocida por instrumentos jurídicos de naturaleza regional en América Latina y por la jurisprudencia de la Corte Interamericana de Derechos Humanos. La citada Convención Belém do Pará en su artículo 9 dispone que:

\footnotetext{
${ }^{7}$ La Resolución 1325 (2000) del Consejo de Seguridad de las Naciones Unidas exhorta a todas las partes en un conflicto armado a que respeten el carácter civil y humanitario de los campamentos y asentamientos de refugiados y a que tengan en cuenta las necesidades especiales de las mujeres y las niñas (Consejo de Seguridad de las Naciones Unidas, 2000: 12)

${ }^{8}$ Véase el análisis que de las Resoluciones del Consejo de Seguridad de las Naciones Unidas sobre violencia sexual y/o de género realizado por Jiménez Sánchez (2017).
}

los Estados Partes tendrán especialmente en cuenta la situación de vulnerabilidad a la violencia que pueda sufrir la mujer en razón, entre otras, de su raza o de su condición étnica, de emigrante, refugiada o desplazada.

En esta misma línea, la Corte Interamericana de Derechos Humanos, en el caso Masacre de Mapiripán vs. Colombia (Sentencia de 15 de septiembre de 2005, Serie C-134, p. 175) estableció que los motivos y las manifestaciones de la vulnerabilidad acentuada en las personas desplazadas son caracterizados desde diversas perspectivas, afirmando que "dicha vulnerabilidad es reforzada por su proveniencia rural y, en general, afecta con especial fuerza a mujeres, quienes son cabezas de hogar y representan más de la mitad de la población desplazadas, niñas y niños, jóvenes y personas de la tercera edad" 9 .

\section{La institucionalización del enfoque ecológico frente a la YSBG: la labor del alto co- misionado de las Naciones Unidas en el ámbito}

Antes de proceder al estudio del marco normativo internacional del derecho a solicitar asilo por motivos de género, conviene hacer una breve mención al progresivo reconocimiento y al enfoque empleado para hacer frente a la VSBG en el ejercicio de su mandato por el ACNUR.

\footnotetext{
${ }^{9}$ Por su parte, el 22 de diciembre de 2010, la CIDH otorgó medidas cautelares a favor de todas las mujeres y niñas desplazadas en 22 campamentos para desplazados internos en Puerto Príncipe, Haití, producto del terremoto ocurrido el 12 de enero de 2010. La Comisión Interamericana solicitó al Estado "asegurar la disponibilidad de adecuados servicios médicos y psicológicos para las víctimas de violencia sexual en lugares que sean accesibles a las solicitantes; proveer seguridad adecuada en los campamentos de desplazados internos, incluyendo iluminación pública, patrullaje adecuado en los alrededores e interior de los campamentos y aumento de mujeres policías en los patrullajes y en las estaciones de policía cercanas; asegurar que los agentes públicos encargados de responder a incidentes de violencia sexual reciban una formación que les permitan dar respuestas adecuadas a las denuncias de delitos de violencia sexual así como proveer la seguridad necesaria en los campos; promover la creación de unidades especiales en la policía judicial y en la fiscalía para la investigación de casos de violación y otras formas de violencia sexual; asegurar que los grupos de base de mujeres tengan plena participación y liderazgo en la planeación y ejecución de políticas y prácticas encaminadas a combatir y prevenir la violación y otras formas de violencia sexual en los campamentos" (CIDH, MC 340/10).
} 
En respuesta a la VSBG, y en línea con los principales organismos internacionales y regionales, el ACNUR ha adoptado el denominado enfoque ecológico. El citado enfoque parte de una perspectiva integral y multidimensional para proceder al análisis de la violencia por motivos de género (Heise, 1998; Krug et al., 2002).

En este orden de términos, conviene subrayar que las teorías ecológicas son relevantes porque parten de la idea de que la violencia contra la mujer y las personas LGBT+ no se reduce al mero resultado de factores singulares individuales, socioculturales o situacionales, "sino que son la consecuencia de la interacción multidimensional entre todos ellos" (Saccomano, 2017: 60).

De acuerdo con el Estatuto del ACNUR establecido en 1950, su mandato abarca la protección todas las personas que se encuentren fuera de su país de origen por temor a la persecución, los conflictos, la violencia generalizada $\mathrm{u}$ otras circunstancias que hayan perturbado gravemente el orden público y que, en consecuencia, requieran de protección internacional $^{10}$.

El trabajo del ACNUR frente a la VSBG cobra relevancia a partir de 1995, año en que publica el documento Violencia Sexual contra las Personas Refugiadas: Guía para la Prevención y Respuesta. Esta guía sirvió para crear una mayor conciencia y comprensión acerca de esta grave violación de derechos humanos y supuso el establecimiento de los cimientos para el desarrollo de programas de prevención y respuesta ante ella (Alto Comisionado de las Naciones Unidas para los Refugiados, 2003: 3).

En el año 2001, tiene lugar en Ginebra la evaluación de los resultados de la aplicación de la Guía en la Conferencia Interagencial Sobre Lecciones Aprendidas en Prevención y Respuesta a la Violencia Sexual y de Género en Situaciones de Refugiados. Y, al año siguiente, el ACNUR publica sus conocidas Directrices sobre la protección internacional: la persecución por motivos de género en el contexto del Artículo 1.A.2) de la Convención de 1951 sobre el Estatuto de los Refugiados y/o su Protocolo de $1967^{11}$.

\footnotetext{
${ }^{10}$ Véase al efecto el documento de la ONU (ONU A/AC.96/830, 7 de septiembre de 1994, párrafos 8,10-11,31$32)$

${ }^{11} \mathrm{El} \mathrm{ACNUR} \mathrm{publica} \mathrm{estas} \mathrm{directrices} \mathrm{en} \mathrm{cumplimiento} \mathrm{de}$ su mandato, de conformidad con el Estatuto de la Oficina del Alto Comisionado de las Naciones Unidas para Refugiados, y el Artículo 35 de la Convención de 1951 sobre el Estatuto de los Refugiados y el Artículo II de su Protocolo de 1967. Estas directrices complementan el Manual sobre Procedimientos y
}

Más recientemente, en el año 2012, el ACNUR elabora una estrategia actualizada de acción contra la VSBG en la que promueve la creación de un marco de protección integral para la protección de los niños y las niñas de interés contra la violencia sexual y/o basada en el género, abordar el sexo por supervivencia como un mecanismo de afrontamiento en situaciones de desplazamiento, involucrar a hombres y niños varones, proporcionar ambiente y acceso seguros a la energía y los recursos naturales internos, proteger a las personas lesbianas, gais, bisexuales, transgénero e intersexuales y a las personas con discapacidad contra la violencia sexual y/o basada en el género.

La cuestión del derecho a la protección internacional frente a la violencia y persecución ejercidas por motivos de orientación sexual e identidad de género fue abordada por el ACNUR por primera vez en el simposio sobre la persecución por razones de género, que fue publicado en un número especial del International Journal of Refugee Law en 1997. Una década después, en 2008, para ofrecer respuesta a las divergencias existentes entre los Estados respecto al reconocimiento de la protección internacional establecida en la Convención de 1951 por estos motivos y frente a la necesidad de ofrecer unos criterios uniformes de interpretación, el ACNUR elabora la Nota de orientación sobre las solicitudes de la condición de refugiado relacionadas con la orientación sexual y la identidad de género ${ }^{12}$.

Posteriormente, en octubre de 2012, el ACNUR publica las Directrices sobre Protección Internacional $n^{0} 9$ el análisis de las solicitudes de la condición de refugiado relacionadas con la orientación sexual y/o la identidad de género en el contexto del artículo 1.A.2)

Criterios para Determinar la Condición de Refugiado en virtud de la Convención de 1951 sobre el Estatuto de los Refugiados y su Protocolo de 1967 (reeditado, Ginebra, enero de 1992). Estas directrices también reemplazan la posición del ACNUR sobre la Persecución por motivo del género (Ginebra, enero de 2000), y son el resultado del Segundo Ámbito de las Consultas Globales sobre el proceso de Protección Internacional, en las cuales se analizó este tema durante la reunión de expertos en San Remo (setiembre de 2001). Estas Directrices tienen como fin servir de guía legal interpretativa a gobiernos, practicantes del derecho, encargados de la toma de decisiones y los jueces, así como al personal del ACNUR encargado de la determinación de la condición de refugiado en el terreno. Un año después, en 2003, el ACNUR publica la Guía de Prevención y Respuesta: violencia sexual y por motivos de género en contra de personas refugiadas, retornadas y desplazadas internas.

${ }^{12}$ Por primera vez, el ACNUR presenta un análisis de los principios jurídicos internacionales, de la jurisprudencia y de otras fuentes pertinentes para "aclarar la legislación y las normas jurídicas aplicables con el fin de orientar en el área temática en cuestión" (Alto Comisionado de las Naciones Unidas para los Refugiados, 2008: 1). 
de la Convención sobre el Estatuto de los Refugiados de 1951 y su Protocolo de 1967, poniendo de manifiesto, por una parte, la relevancia que para este organismo tiene este colectivo de personas refugiadas y, por otra, la evidente necesidad de armonizar las prácticas y los criterios interpretativos sobre esta materia.

\section{El doble reconocimiento de la VSBG en el marco jurídi- co del Derecho Internacional de los Refugiados}

Una de las principales obligaciones de los Estados frente a la VSBG consiste en el reconocimiento del estatuto de refugiada a aquella persona que tiene un fundado temor a ser perseguida por motivos de género.

De acuerdo con el artículo 1.A.2) de la Convención sobre el Estatuto de los Refugiados, firmada en Ginebra en 1951, el término "refugiado" se aplica a toda persona:

\begin{abstract}
que, como resultado de acontecimientos ocurridos antes del 1 de enero de 1951 y debido a fundados temores de ser perseguida por motivos de raza, religión, nacionalidad, pertenencia a determinado grupo social u opiniones políticas, se encuentre fuera del país de su nacionalidad y no pueda o, a causa de dichos temores, no quiera acogerse a la protección de tal país; o que, careciendo de nacionalidad y hallándose, a consecuencia de tales acontecimientos, fuera del país donde antes tuviera su residencia habitual, no pueda o, a causa de dichos temores, no quiera regresar a él.
\end{abstract}

Las dificultades del denominado Derecho Internacional de los Refugiados para proteger a las mujeres y a las personas LGBT+ refugiadas vienen derivadas "de su anacronismo y del tradicional anclaje de las normas internacionales a los esquemas patriarcales" (Charlesworth et al., 1992: 613).

De hecho, la definición de persona refugiada de la Convención de 1951 proviene de los esfuerzos de los países occidentales por dar prioridad a la protección a las personas cuya huida era motivada por la persecución de los valores políticos pro-occidentales (Hathaway, 1991: 6). De este modo, la concisa formulación de los motivos de persecución: raza, religión, nacionalidad, opinión política o pertenencia a un determinado grupo social, excluía cualquier posibilidad de que la Convención pudiera ser empleada por el bloque soviético para sus fines políticos.

Con el Protocolo de 1967, la definición de refugiado se universaliza, al menos a efectos formales, superando los límites tanto temporal como geográfico de la Convención de 1951. Sin embargo, la definición no se amplía a nuevos motivos, como por ejemplo el género, y solo aquellas personas que huyen por una persecución de tipo civil o política pueden encontrar refugio, excluyéndose de facto, a la mayoría de las personas refugiadas de los países en vías de desarrollo, cuya huida se debe principalmente a desastres naturales, a conflictos bélicos o a crisis económicas y políticas que no responden directamente a los parámetros occidentales de persecución (Lentini, 1985: 11).

En la aplicación de la perspectiva de género al Derecho Internacional de los Refugiados, nos encontramos con un reconocimiento doble de la VSBG en el marco del reconocimiento del estatuto de persona refugiada, tal como ha diferenciado la doctrina especializada (Kneebone, 2005: 23; Ankenbrand, 2002: 47).

En primer lugar, de acuerdo con una interpretación evolutiva de la normativa en función de la realidad social, puede reconocerse como persona refugiada a aquella persona que manifiesta un fundado temor a ser perseguida por motivos vinculados al género, siendo éste la causa principal que justifica su necesidad de huida y su posterior categorización dentro del art.1.A.2) de la Convención de Ginebra de 1951, principalmente en cuanto perteneciente a un "grupo social determinado", categoría que será objeto de análisis crítico en un posterior apartado del presente trabajo.

En segundo lugar, se encuentran aquellas personas refugiadas cuyo estatuto es reconocido con independencia de su género, pero que, durante la huida, el tránsito y/o la acogida son víctimas de VSBG (Jiménez Sánchez, 2017: 5). Dentro de este segundo supuesto se encuadra el concepto de origen anglosajón de generización de la persecución para reconocer las múltiples vulnerabilidades que las mujeres y las personas LGBT+ pueden sufrir a lo largo de todo el proceso de asilo.

A continuación, se procede al análisis de ambos supuestos en el marco de la política de asilo de la UE, así como de su normativa reguladora. A tal efecto, se presenta, previamente, un breve análisis de los datos 
oficiales relativos a las solicitudes de protección internacional de la UE estudiados desde el enfoque de género.

\section{Los datos de las solicitudes de protección internacional presentadas en la Unión Eu- ropea desde una perspectiva de género}

De acuerdo con los datos publicados por la Agencia Eurostat de la Unión Europea en relación con las solicitudes de protección internacional presentadas en la UE, desde la consideración de los indicadores de género, se observa como en 2017 fueron más hombres que mujeres las personas solicitantes de protección internacional.

Entre las personas solicitantes más jóvenes, en edades comprendidas de los 0 a los 13 años, las mujeres solicitantes representaron el $48 \%$ del número total en 2017. Sin embargo, se puede destacar un mayor grado de desigualdad de género en relación con las solicitudes presentadas por personas de 14 a 17 años y de 18 a 34 años de edad, sectores en los que casi las tres cuartas partes de las personas solicitantes fueron hombres. Además, esta relación desciende a más de las tres quintas partes para el grupo de personas solicitantes de 35 a 64 años de edad. En la UE de los 28, las mujeres solicitantes de protección internacional solo superaron en número a los hombres solicitantes en el sector poblacional de mayores de 65 años, aunque este grupo apenas represente el 0,6\% del número total de aquellas personas que solicitan por primera vez la protección internacional (Unión Europea y Agencia Eurostat, 2018).

Estos datos revelan el mayor protagonismo en el proceso de asilo de los hombres frente al de las mujeres solicitantes de asilo. No podemos obviar que las mujeres, desde una óptica interseccional, se enfrentan a múltiples barreras económicas, sociales, jurídicas, culturales y religiosas que les dificulta el acceso a los procesos migratorios y de asilo. En esta línea, destaca la labor de Jordan et al. (2012) cuyo análisis se centra en subrayar las divergencias existentes entre las experiencias vividas por las solicitantes mujeres y aquellas vividas por los solicitantes hombres (Jordan et al., 2012: 2).

Por su parte, del análisis de las cifras aportadas por el Ministerio del Interior del Gobierno de España, se destaca como el $41 \%$ de las personas solicitantes de asilo en el año 2016 fueron mujeres (6.718 mujeres en total). En relación con las personas solicitantes de asilo procedentes de América Latina (la región de la que procedieron en el año 2016 el mayor número de solicitudes de protección internacional en España), de un total de 6.017 solicitantes latinoamericanos casi la mitad fueron mujeres (2.864), siendo los países de mayor procedencia de mujeres solicitantes de asilo latinoamericanas Venezuela (con mucha diferencia al resto de países, con 2.074 mujeres solicitantes de asilo), Colombia (289 mujeres solicitantes), El Salvador (200 mujeres solicitantes) y Honduras (182 mujeres solicitantes) (Ministerio del Interior y Gobierno de España, 2017: 13).

Sin embargo, y a pesar de los alarmantes índices de VSBG perpetrada en diferentes países de América Latina, los datos publicados por el Ministerio de Interior español revelan el limitado reconocimiento de las solicitudes de asilo y de protección subsidiaria procedentes de mujeres de dicha región. En el año 2016, solo a 10 mujeres procedentes de América Latina se les reconoció la condición de refugiada y la consecuente concesión del derecho de asilo y solo a 2 mujeres se les reconoció la protección subsidiaria (Ministerio del Interior y Gobierno de España, 2017: 53) ${ }^{13}$.

Por su parte, datos más recientes de 2017, elaborados por la Comisión Española de Ayuda al Refugiado (CEAR), revelan que el $43 \%$ de las personas solicitantes de asilo en el año pasado fueron mujeres, ascendiendo a 13.155 el número de mujeres solicitantes de protección internacional. El mismo estudio publica que están pendientes de resolución 13.425 solicitudes procedentes de Venezuela, 2.895 solicitudes de Colombia, 1.555 solicitudes de El Salvador y 1.450 solicitudes de Honduras (Comisión Española de Ayuda al Refugiado, 2018) ${ }^{14}$.

A pesar de que los Estados miembros de la Unión Europa deban publicar estadísticas desagregadas por el género de las personas solicitantes (Unión Europea y Parlamento Europeo, 2016: 3), una de las principales críticas en relación la publicación de los datos

\footnotetext{
${ }^{13}$ Sin embargo, del análisis de estas cifras, por muy reducidas que puedan considerarse, debe destacarse que no obedecen a un criterio de discriminación directa por el género de los solicitantes dado que, en España, en ese mismo año 2016, solo se reconocieron 8 estatutos de refugiados a hombres procedentes de América Latina y solo se le reconoció la protección subsidiaria a 1 hombre procedente de la misma región (Ministerio del Interior y Gobierno de España, 2017: 53)

${ }^{14}$ Véase el estudio completo y actualizado en la página web: http://www.masquecifras.org/
} 
relativos a las política de asilo de la UE consiste en que tales datos no revelan los motivos de persecución por los que solicita la protección internacional, imposibilitándose el análisis del número de solicitudes presentadas por mujeres y por personas LGBT+ por tener un fundado temor a ser perseguidas por motivos de género $y$, en consecuencia, el estudio de la relevancia y el impacto de este tipo de persecución en el marco de la protección internacional reconocida por los Estados miembros de la UE.

\section{La política de asilo de la UE: del proceso de securitariza- ción a la necesidad de una aplicación transversal de la perspectiva de género}

La política de asilo de la Unión Europea responde a los valores que fundamentan su existencia como organización internacional de naturaleza sui generis entre los que se encuentra el respeto a los derechos humanos y a las libertades fundamentales. El artículo 2 del Tratado de la Unión Europea, integrado en el Tratado de Lisboa de diciembre de 2009, establece que:

La Unión se fundamenta en los valores de respeto de la dignidad humana, libertad, democracia, igualdad, Estado de Derecho y respeto de los derechos humanos, incluidos los derechos de las personas pertenecientes a minorías.

Sin embargo, lamentablemente, la política de asilo de la UE es víctima del proceso de securitarización que adolece también la política migratoria de la Unión Europea. La preocupación manifiesta del legislador comunitario por el abuso del derecho a solicitar protección internacional por los denominados migrantes económicos y el temor de los Estados miembros a un uso indebido del proyectado espacio de libertades por el crimen internacional han propiciado "la emergencia de una acción comunitaria restrictiva respecto del asilo y del refugio" (Trujillo Herrera, 2003: 455).

Nos encontramos, siguiendo al concepto desarrollado por Caloz-Tschopp (1997), ante una démocratie sécuritaire en la que, a nivel fáctico, más allá de la retórica institucional, lo que prima es la protección de nuestro espacio interior común frente a las potenciales amenazas que pueden implicar los flujos migratorios exteriores (Caloz-Tschopp, 1997: 20).

La política de asilo se contamina de esta vinculación con la política migratoria y del miedo que subyace al abuso del derecho de asilo y al efecto llamada que este derecho puede tener sobre otras personas refugiadas legitimadas para solicitar protección internacional. Nos entramos, por tanto, ante una política de asilo de la UE que requiere, como destaca Mahamut (2016), hacer del actual Sistema Europeo Común de Asilo "un sistema más equitativo, eficiente, sostenible, basado en normas comunes que responda a un reparto más justo de responsabilidades entre los distintos Estados miembros de la UE" (Mahamut, 2016: $233)^{15}$.

Partiendo de esta necesidad, y con objeto de superar el proceso de securitarización y la imperante falta de solidaridad entre los Estados miembros desde la que en la práctica opera la política de asilo de la UE, todos los elementos constituyentes de dicha política pública requieren de una aplicación y revisión transversal, integral y crítica desde la perspectiva de género.

\section{La YSBG como causa de persecución en la normativa reguladora de la política de asilo de la Unión Europea}

La Directiva 2011/95/EU de la Unión Europea, por la que se establecen las normas relativas a los requisitos de reconocimiento de nacionales de terceros países o apátridas como beneficiarios de protección internacional (estatuto de refugiado y protección subsidiaria), reconoce la VSBG como motivo de persecución $\operatorname{legítimo}^{16}$.

\footnotetext{
${ }^{15}$ Para profundizar en la cuestión sobre los desafíos actuales del Sistema Europeo Común de Asilo frente a las crisis humanitarias véase el pertinente análisis que sobre la materia realiza Mahamut (2016) en el artículo titulado "La ductilidad del derecho a la protección internacional (refugio y protección subsidiaria) ante las crisis humanitarias: un desafío para Europa y para el Sistema Europeo Común de Asilo". Teoría y Realidad Constitucional, núm. 38, 2016, pp. 211-238.

${ }^{16}$ De este modo, dispone que se tendrán en cuenta las cuestiones relacionadas con el género del solicitante, "incluida la identidad de género y la orientación sexual, que pueden estar vinculadas a ciertas tradiciones jurídicas y costumbres de las que puede derivarse, por ejemplo, la mutilación genital, la esterilización forzada o el aborto forzado" (Parlamento Europeo, 2011: 30)
} 
Sin embrago, la consideración del género como causa de persecución no se opera de forma autónoma como causa por sí mismo, sino que se articula de forma vinculada al motivo de pertenencia a un grupo social determinado. En relación con el contenido de esta categoría, el ACNUR define un grupo social determinado como:

un grupo de personas que comparte una característica común distinta al hecho de ser perseguidas o que son percibidas a menudo como grupo por la sociedad. La característica será innata e inmutable, o fundamental de la identidad, la conciencia o el ejercicio de los derechos humanos.

\section{(Alto Comisionado de las Naciones Unidas} para los Refugiados, 2002: 11).

Por tanto, son dos los elementos que constituyen la pertenencia a un grupo social determinado:

- El elemento de la "característica protegida" que examina si un grupo está unido o por una característica innata o inmutable o por una característica tan fundamental para la dignidad humana que ninguna persona deba ser obligada a renunciar a la misma.

- El elemento de la "percepción social" que da prioridad a si un determinado grupo social comparte una característica común que hace que sea identificado o considerado como distinto dentro de la sociedad en la que se inserta ${ }^{17}$.

La categorización del género como causa de persecución en cuanto elemento que conforma un grupo

\footnotetext{
${ }^{17}$ Algunos autores como HATAHWAY, del mismo modo que lo han hecho los tribunales de Estados Unidos, Reino Unido y Bélgica, entre otros, otorgan más peso en el reconocimiento de la pertenencia a un grupo social determinado a aquellas circunstancias que sean innatas o históricas y, por tanto, inmutables, o a aquéllas que aun pudiéndose modificar no se debe exigir sobre ellas tal cambio por estar estrechamente vinculadas a la identidad de la personas o al ejercicio y disfrute de los derechos humanos fundamentales (Díaz Lafuente, 2016: 91).

- En contra, autores como Goodwin-Gill (1986), centran el foco de atención sobre la percepción que tiene el perseguidor o la sociedad en su conjunto sobre determinadas personas en función de cierto atributo, actividad, creencias o interés determinado que las identifica como grupo social diferenciado (Goodwin-Gill, 1986: 45). El ACNUR, por su parte, ha resuelto este debate doctrinal y jurisprudencial entendiendo que los dos enfoques para identificar los grupos sociales determinados operan de forma alternativa y no acumulativa (Alto Comisionado de las Naciones Unidas para los Refugiados, 2012: 45)
}

social determinado genera múltiples desafíos tanto a nivel teórico como en la práctica del proceso de asilo.

A este respecto, conviene subrayar que la consideración del género, de la orientación sexual o de la identidad de género en cuanto características innatas o inmutables, produce una serie de conflictos tanto a nivel teórico, frente a nuevas teorías de la sexualidad y del género como la teoría queer que parte de la disidencia sexual y de la deconstrucción de las identidades estigmatizadas para reafirmar que la libertad sexual como un derecho humano, como a nivel procesal en el procedimiento de asilo llevado a cabo por las autoridades del Estado receptor para el potencial reconocimiento de la protección internacional (Díaz Lafuente, 2016: 93$)^{18}$.

Además, en la citada Directiva se observan una serie de elementos en los que claramente se manifiesta una clara discriminación de los motivos de género frente a los otros motivos de persecución, lo que revela la óptica androcréntrica desde la que se articulan los elementos vinculados al género.

La primera restricción la encontramos al inicio del artículo 10, apartado 1, letra d, según el cual puede incluirse el género y la orientación sexual dentro de la categoría de grupo social determinado solo "en función de las circunstancias imperantes en el país de origen". Esta vinculación de los motivos de género y orientación sexual a las circunstancias del país de origen exige el conocimiento necesario por parte de las autoridades nacionales competentes para el reconocimiento de la protección internacional de la situación de cada país respecto al tratamiento otorgado a las mujeres y a las personas LGBT+, lo que en muchas ocasiones ha servido de justificante para denegar sistemáticamente las solicitudes de protección internacional por tales motivos ${ }^{19}$.

La segunda restricción se establece en la misma disposición al introducir que "no podrá entenderse la orientación sexual en un sentido que comporte actos considerados delictivos por la legislación nacional de los Estados miembros". Esta restricción resulta innecesaria, ambigua y claramente discriminatoria, con-

\footnotetext{
${ }^{18}$ De este modo, debe tenerse en cuenta que el tratamiento del género y de la sexualidad en un marco transnacional y multicultural requiere una contextualización de los parámetros de espacio y tiempo en relación con las circunstancias particulares y con las experiencias vividas de cada solicitante.

${ }^{19}$ Además, esta condición de valorar la persecución en función de las circunstancias imperantes en el país de origen discrimina los motivos de género frente a los otros motivos objeto de protección internacional; raza, religión, nacionalidad u opiniones políticas, ante los que no se requiere tal contextualización de la persecución (Díaz Lafuente, 2016: 135)
} 
tribuyendo a la generación de una percepción errónea y estigmatizadora de la orientación sexual, dado que la propia Directiva de reconocimiento en su artículo 12 ya prevé entre los supuestos de exclusión la comisión de delitos graves comunes aplicable a todos los motivos de persecución (Díaz Lafuente, 2016: 136) ${ }^{20}$

Por su parte, en cuanto a la consideración de la VSBG como constituyente de acto de persecución que legitima el reconocimiento de la protección internacional, la Directiva de Reconocimiento se expresa en términos taxativos ya que en su artículo 9, apartado $2^{\underline{O}}$, establece en un listado numerus apertus de ejemplos que constituyen persecución objeto de protección internacional y entre los que se incluyen:

- los actos de violencia física o psíquica, incluidos los actos de violencia sexual,

- las medidas legislativas, administrativas, policiales o judiciales que sean discriminatorias en sí mismas o que se apliquen de manera discriminatoria,

- los procesamientos o penas que sean desproporcionados o discriminatorios,

- la denegación de tutela judicial de la que se deriven penas desproporcionadas o discriminatorias,

- los procesamientos o penas por la negativa a cumplir el servicio militar en situaciones de conflicto,

- los actos dirigidos contra las personas por razón de su género o por ser niños.

En relación con el reconocimiento de los motivos de género para invocar la protección internacional, de acuerdo con el Comité para la Eliminación de la Discriminación contra la Mujer, se han incluido como constitutivos de persecución "la amenaza de mutilación genital femenina, el matrimonio forzoso o a edad

\footnotetext{
${ }^{20}$ Este inciso es claramente ambiguo porque la orientación sexual en sí misma no tiene por qué implicar ninguna conducta tipificada como delito. En este sentido, la inclusión de este inciso parece responder a una carencia objetiva en la comprensión de la naturaleza y el contenido del término orientación sexual y supone una clara incursión por parte del legislador europeo en prejuicios discriminatorios que parecen vincular indirectamente la orientación sexual con conductas tipificadas penalmente en Europa como son los delitos de agresión sexual, agresiones y abusos a menores, acoso sexual, los delitos de exhibicionismo y provocación sexual y aquellos relativos a la prostitución y corrupción de menores, sobre los resulta independiente la orientación sexual de quien comete tales actos (Díaz Lafuente, 2016: 137).
}

temprana, la amenaza de violencia o los denominados delitos de honor, la trata de mujeres, los ataques con ácido, la violación y otras formas de agresión sexual, las formas graves de violencia doméstica, la imposición de la pena capital u otras penas físicas contempladas en los sistemas de justicia discriminatorios, la esterilización forzada, como la persecución política o religiosa por manifestar opiniones feministas o de otra índole y las consecuencias persecutorias de no acatar las normas y convenciones sociales prescritas en relación con el género o por reivindicar sus derechos fundamentales" (Comité para la Eliminación de la Discriminación contra la Mujer, 2014: 6).

Uno de los principales debates doctrinales que se han generado sobre esta materia es el establecimiento de la gravedad de la VSBG por la que debe reconocerse la protección internacional.

El artículo 9 de la citada Directiva destaca que constituirán objeto de persecución aquellos actos que:

sean suficientemente graves por su naturaleza o carácter reiterado como para constituir una violación grave de los derechos humanos fundamentales, en particular los derechos que no puedan ser objeto de excepciones al amparo del artículo 15, apartado 2, del Convenio Europeo para la Protección de los Derechos Humanos y de las Libertades Fundamentales.

Es decir, aquellos actos que de forma grave o reiterada violen el derecho a la vida, impliquen tortura, penas o tratos inhumanos o degradantes y supongan alguna forma de esclavitud o servidumbre.

Sin embargo, la Directiva matiza que también podrá ser entendida como constituyente de objeto de persecución la acumulación de varias medidas, incluidas las violaciones de los derechos humanos, que sean lo suficientemente graves como para afectar a una persona de manera similar a la vulneración de los derechos antes citados. En esta línea, debe afirmarse que incluso los abusos menos explícitos deberían ser suficientes, dependiendo de su naturaleza y severidad, y especialmente si se prueba su carácter reiterado (Goodwin-Gill y McAdam, 2007: 92) ${ }^{21}$.

\footnotetext{
${ }^{21} \mathrm{~A}$ este respecto, la jurisprudencia del Tribunal Supremo de España también ha considerado como formas específicas de persecución los abusos constantes y severos y la violencia sexual y/o basada en el género. Véanse al efecto las Sentencias del Tribunal Supremo de 10 de noviembre de 2005, de 9 de septiembre de 2005 y de 22 de diciembre de 2006. Del mismo modo, véase sobre la temática la Sentencia del Tribunal Supremo de 19 de septiembre de 2011 y la Sentencia de la Au-
} 


\section{La vulnerabilidad múltiple de las personas solicitantes de protección internacional por motivos de género en el procedimiento de asilo y en la acogida en los países re- ceptores}

La generización del proceso de asilo pone de manifiesto el hecho de que las mujeres y las personas LGBT + refugiadas, con independencia de si la protección internacional sea reconocida por motivos de género o por otro de los motivos previstos en el art. 1.A2) de la Convención de Ginebra, pueden sufrir vulneraciones de sus derechos fundamentales a lo largo de todo el proceso de asilo: desde los propios motivos que activan la huida, en las rutas de tránsito hasta llegar al país receptor, en los centros de recepción y acogida y, en el caso de su posterior reconocimiento de la protección internacional, en la aplicación de los mecanismos de integración social de las mujeres y personas LGBT + refugiadas o beneficiarias de la protección subsidiaria.

La discriminación y la violencia por motivos de género, en muchas ocasiones, persiste en los países receptores de asilo. De hecho, la VSBG se presenta como la forma más extendida de violencia entre las personas refugiadas y desplazadas (Jiménez Sánchez, 2017: 103).

En este sentido, conviene destacar que en los países miembros de la Unión Europea los índices de violencia de género también son alarmantes. De acuerdo con la Agencia de Derechos Fundamentales de la Unión Europea, "el 43 por ciento de las mujeres de los 28 Estados Miembros de la Unión Europea han sufrido algún tipo de violencia psicológica por parte de un compañero sentimental a lo largo de su vida" (Agencia de los Derechos Fundamentales de la Unión Europea, 2014: 71$)^{22}$.

diencia Nacional. Sala de lo Contencioso-Administrativo de 13 de enero de 2009.

Para el análisis del reconocimiento de la violencia doméstica en la práctica del asilo véase ARENAS HIDALGO, N. "La "violencia domésticaz la posibilidad de adquirir el estatuto de refugiado: derecho comunitario y práctica española". Revista de derecho migratorio y extranjería, № $.17,2008$

${ }^{22}$ Además, una de cada 10 mujeres de la Unión Europea declara haber sufrido ciberacoso desde la edad de los 15 años, lo que incluye haber recibido correos electrónicos o mensajes SMS no deseados, sexualmente explícitos y ofensivos, o bien intentos inapropiados y ofensivos en las redes sociales. El mayor
La Directiva 2013/32/UE sobre procedimientos comunes para la concesión o la retirada de la protección internacional, en adelante la Directiva de Procedimiento, prevé una serie de medidas que afectan de forma positiva a las personas solicitantes de asilo y protección subsidiaria por motivos de género. Mucho más sensible que su versión anterior, la citada Directiva introduce una serie de parámetros mínimos y de obligaciones para los Estados miembros respecto a las garantías necesarias para las mujeres y las personas $\mathrm{LGBT}+$.

En primer lugar, la Directiva de Procedimiento requiere a los Estados miembros la adopción de mecanismos de identificación para aquellas personas vulnerables, entre las que se incluyen aquellas perseguidas por motivos de género. La norma define como solicitante con necesidad de garantías procesales especiales a "aquellas cuya capacidad para beneficiarse de los derechos y cumplir con las obligaciones establecidos en la Directiva es limitada debido a circunstancias personales". Además, el preámbulo de la Directiva reconoce explícitamente en su considerando vigesimonoveno que algunas personas solicitantes pueden necesitar garantías procesales especiales en función de "su edad, género, orientación sexual, identidad de género, discapacidad, enfermedad grave o desorden mental".

Del mismo modo, también afirma que dichas garantías procesales especiales podrán ser requeridas a consecuencia de haber sufrido tortura o alguna forma de violencia física, psicológica o sexual. De este modo, cuando un Estado miembro reciba una solicitud de protección internacional, deberá comprobar si la persona solicitante necesita de las garantías especiales de naturaleza procesal enumeradas en la Directiva de Procedimiento ${ }^{23}$.

riesgo afecta a las mujeres jóvenes de entre 18 y 29 años de edad (Agencia de los Derechos Fundamentales de la Unión Europea, 2014: 109)

23 Respecto a la obligación del Estado miembro de identificar a las personas necesitadas de garantías procesales especiales el considerando $\mathrm{n}^{0} 29$ de la Directiva 2013/32/EU establece que: "Algunos solicitantes pueden necesitar garantías procedimentales especiales por razón, entre otros, de su edad, género, orientación sexual, identidad de género, discapacidad, enfermedad grave, enfermedad mental o consecuencias de torturas, violación u otras formas graves de violencia psicológica, física o sexual. Los Estados miembros deben esforzarse por identificar a los solicitantes necesitan garantías procedimentales especiales antes de que se adopte la resolución en primera instancia. A estos solicitantes se les debe prestar el respaldo adecuado, incluyendo el tiempo necesario, a fin de crear las condiciones necesarias para que tengan efectivamente acceso a los procedimientos y puedan presentar los elementos necesarios para fundamentar su solicitud de protección internacional". 
A tal efecto, la falta de identificación de aquellas personas solicitantes de asilo considerados como grupos vulnerables afecta gravemente a la efectividad del Sistema Europeo Común de Asilo, así como a la potencialidad del debido reconocimiento de la protección internacional (Parlamento Europeo, 2012: 81). Es por ello que la identificación temprana y adecuada de las personas solicitantes de protección internacional por motivos de género resulta un factor clave para el correcto funcionamiento de la política europea de asilo.

En esta línea, debe destacarse que el marco jurídico actual de la UE solo aborda estas cuestiones de forma tangencial siendo necesario un tratamiento integral que armonice los procedimientos de identificación de los grupos vulnerables, así como los principios comunes que garanticen una valoración efectiva y garantista de las solicitudes de protección internacional por motivos de género (Wijnkoop y Vloeberghs, 2010).

En segundo lugar, la Directiva de Procedimiento establece como obligatoria la entrevista personal. A este respecto, el Comité para la Eliminación de la Discriminación contra la Mujer ha manifestado su preocupación sobre la práctica realizada en muchos sistemas de asilo en los que se examina "con una perspectiva machista las solicitudes del estatuto de refugiado presentadas por las mujeres, lo que a veces da lugar a que dichas solicitudes no se evalúen correctamente o se denieguen" (Comité para la Eliminación de la Discriminación contra la Mujer, 2014: 7).

La entrevista debe realizarse incluso para la determinación de la admisibilidad a trámite de la solicitud, algo que no se realiza en todos los Estados miembros y que es de esencial relevancia para que las personas solicitantes por motivos de género puedan expresar el origen de su persecución. Además, en contra de la práctica de muchos Estados miembros, la norma comunitaria exige desarrollar un informe detallado sobre la entrevista personal ${ }^{24}$.

Desde una perspectiva de género, resulta fundamental que todos los agentes que intervienen en el proceso de asilo; fuerzas y cuerpos de seguridad del Estado, instructores y demás operadores jurídicos, re-

\footnotetext{
${ }^{24}$ La Directiva dispone, en su artículo 15.3, que los Estados miembros se asegurarán de que la persona que vaya a celebrar la audiencia sea suficientemente competente para tener en cuenta "las circunstancias personales o generales de la solicitud, incluidas las raíces culturales, e género, la orientación sexual, la identidad de género o la vulnerabilidad del solicitante". La inclusión de la orientación sexual y de la identidad de género en este apartado es uno de los principales avances que en este ámbito introduce la nueva versión de la Directiva de procedimientos con respecto a la anterior.
}

ciban una formación adecuada inclusiva de la perspectiva de género necesaria para garantizar los derechos fundamentales de la persona solicitante. La norma comunitaria requiere, en este sentido, formación obligatoria para las autoridades competentes, partiendo del Currículo Europeo de Asilo (CEA) de la Oficina Europea de Apoyo al Sistema Europea Común de $\mathrm{Asilo}^{25}$.

\section{Consideraciones finales: la prueba procesal, las condi- ciones de acogida y la con- sideración de terceros países seguros desde la perspectiva de género}

Son múltiples y de variada naturaleza los elementos vinculados con la protección internacional que deben ser revisados, regulados y aplicados desde el enfoque de género. Siendo consciente las limitaciones del presente trabajo, en este último apartado, se arrojará luz sobre tres de las cuestiones en las que observa una mayor vulnerabilidad por parte de las mujeres y personas LGBT+ solicitantes de protección internacional y que, en consecuencia, requieren de una serie de garantías procesales especiales para el reconocimiento efectivo del derecho a solicitar asilo: la prueba de su testimonio, la consideración de país seguro y las condiciones de acogida en los centros de recepción de personas solicitantes de protección internacional.

En primer lugar, respecto a la consideración de los llamados terceros países seguros, la citada norma comunitaria establece que esta categorización no debe operar como una garantía absoluta para la seguridad de los nacionales de aquel país ${ }^{26}$.

\footnotetext{
${ }^{25} \mathrm{El}$ considerando $\mathrm{n}^{0} 16$ de la Directiva de Procedimiento dispone, en este sentido, que "es esencial que las decisiones relativas a todas las solicitudes de protección internacional se tomen sobre la base de los hechos y, en primera instancia, por las autoridades cuyo personal tenga el conocimiento adecuado o reciba la formación necesaria en el ámbito de la protección internacional." El artículo 34.2, de este modo, establece que "los Estados miembros asegurarán que el personal responsable de llevar a cabo las audiencias reciba la formación básica necesaria, especialmente respecto al derecho internacional de los derechos humanos, al derecho comunitario de asilo y a las técnicas para la realización de entrevistas".

${ }^{26} \mathrm{El}$ considerando $\mathrm{n}^{\mathrm{0}} 42$ de la Directiva de Procedimiento establece que" la designación de un tercer país como país de origen seguro no podrá, a los fines de la presente Directiva, establecer una garantía absoluta de seguridad para los nacionales de dicho país. Por su propia naturaleza, la evaluación
} 
Este aspecto es de suma relevancia para la concesión de la protección internacional, en cuyo núcleo duro se halla el principio de non-refoulement, por motivos de género de personas procedentes de los denominados países seguros en muchos de los cuales, a pesar de su consideración, se constatan altos índices de persecución, abuso físico, psíquico y sexual, actos de violencia y de discriminación grave por motivos de género.

La citada norma establece de forma taxativa que cuando un/a solicitante demuestre que existen válidas razones para considerar que un país no es seguro respecto a sus circunstancias individualizadas, la designación de tal país como seguro no le será aplicable.

Esta cuestión adquiere una especial transcendencia también en relación con la externalización de la acogida de personas refugiadas que la UE ha canalizado a Turquía, uno de los países con mayores índices de VSBG y de LGBTIfobia de acuerdo con los instrumentos y mecanismos internacionales y regionales de derechos humanos, y la redistribución en masa a ese país de cientos de miles de personas refugiadas, el $55 \%$ mujeres y niños, acordada por el Consejo de la UE el 7 de marzo de $2016^{27}$.

En segundo lugar, otra de las cuestiones que más debate ha suscitado tanto a nivel doctrinal como institucional reside en el uso de pruebas médicas para acreditar la credibilidad del relato. Siguiendo a Jiménez Sánchez (2017), "entender las dificultades de la prueba de la violencia basada en el género en un contexto de huida y persecución y la necesidad de ofrecer una atención psicológica adecuada durante las entrevistas es fundamental si no se quiere lesionar gravemente el derecho de asilo de las mujeres que huyen por motivos relacionados con su género, ya que resulta más compleja aún la conclusión favorable de dichas solicitudes" (Jiménez Sánchez, 2017: 10).

En este sentido, de acuerdo con lo dispuesto en la Directiva de Procedimiento, puede afirmarse que las

que sustenta la designación solo puede tener en cuenta las circunstancias civiles, jurídicas y políticas generales de dicho país y el hecho de si los agentes de la persecución, la tortura, el trato inhumano o degradante o los castigos están sometidos a sanción en la práctica cuando se los considera responsables en dicho país. Por dicho motivo, es importante que, cuando un solicitante demuestre que existen motivos válidos para que no se considere a un país como seguro en sus circunstancias particulares, la designación del país como seguro ya no puede considerarse en cuanto a lo que dicho solicitante se refiere"

${ }^{27}$ Consúltese la Declaración conjunta del Consejo de la UE y Turquía de 7 de marzo de 2016 en la página web: http://www.consilium.europa.eu/es/press/pressreleases/2016/03/18/eu-turkey-statement/ pruebas médicas deben caracterizarse por los siguientes elementos:

1. La obligatoriedad de la prestación del consentimiento voluntario y libre del solicitante. Si el solicitante se negase a proceder a la prueba médica dicha conducta no puede fundamentar ningún indicio de prueba ni afectar a la concesión o denegación de la protección internacional.

2. El absoluto respeto a la dignidad del individuo y a sus derechos fundamentales, tales como el de derecho a la integridad física y psicológica o el derecho a la intimidad. Además, la prueba médica deberá ser lo menos invasiva posible.

3. La cualificación profesional médica. El examen médico deberá ser realizado por profesionales médicos cualificados que puedan garantizar la fiabilidad del resultado.

4. La gratuidad de la prueba médica. A menos que el solicitante desee hacerse el examen con otros profesionales o en otro momento al indicado por las autoridades competentes, será el Estado receptor el que corra con los gastos de la prueba médica.

En relación la regulación comunitaria de la prueba y con los elementos para verificar la credibilidad del relato de una persona que alega sufrir grave temor de persecución por motivos de su orientación sexual y/o su identidad de género se ha pronunciado el Tribunal de Justicia de la Unión Europea en la sentencia de 2 de diciembre de $2014^{28}$.

Por último, conviene mencionar los avances que, en materia de género, recoge la Directiva de Acogida por la que se establecen las normas mínimas comunes sobre las condiciones de vida de las personas solicitantes de protección internacional y por la que se aseguran que tengan acceso a una vivienda, a un empleo, a una alimentación adecuada, a los servicios de asistencia sanitaria o de atención médica y psicológica.

Dicho instrumento jurídico obliga a los Estados miembros a atender las necesidades especiales de acogida que requieren las personas vulnerables, entre las que se encuentran aquellas personas perseguidas por su género. De hecho, por primera vez, establece los criterios mínimos comunes de recepción de las personas solicitantes de protección internacional, obligando a los Estados miembros a que se aseguren de que

\footnotetext{
${ }^{28}$ Véase al efecto el análisis de la citada sentencia realizado por (Díaz Lafuente, 2016: 173).
} 
los derechos fundamentales de tales personas estén plenamente garantizados, prestando especial atención a las personas vulnerables entre las que se encuentran las personas perseguidas por motivos de género. Además, el artículo 18.4 de la citada norma dispone que los Estados miembros adoptarán las medidas adecuadas para prevenir el acoso y los actos de violencia de género, incluidos la violencia y el acoso sexuales, en los locales y centros de acogida a los que se refiere el apartado 1, letras a) y b) de la citada disposición ${ }^{29}$.

La cuestión del establecimiento de las garantías necesarias para la acogida de las mujeres y personas LGBT+ en los centros de recepción reviste de una importancia fundamental no solo a efectos de evitar posibles supuestos de victimización secundaria sino, además, para garantizar el adecuado y efectivo funcionamiento de todo el engranaje del proceso de asilo. Al efecto, conviene subrayar que el Comité para la Eliminación de la Discriminación contra la Mujer, en sus observaciones finales sobre los informes periódicos séptimo y octavo combinados de España emitidas en 2017, ha confirmado la necesidad de trabajar para la prevención y respuesta ante el acoso y la violencia sexual y de género en los Centros de Migraciones españolas (CAR y CETI) Comité para la Eliminación de la Discriminación contra la Mujer $(2014)^{30}$.

\footnotetext{
${ }^{29}$ En esta misma línea, el artículo 21 de la nueva Directiva dispone que: "en la legislación nacional por la que se apliquen las disposiciones de la presente Directiva, los Estados miembros tendrán en cuenta la situación específica de las personas vulnerables tales como menores, menores no acompañados, personas con discapacidades, personas de edad avanzada, mujeres embarazadas, familias monoparentales con hijos menores, víctimas de la trata de seres humanos, personas con enfermedades graves, personas con trastornos psíquicos y personas que hayan padecido torturas, violaciones $u$ otras formas graves de violencia psicológica, física o sexual, como las víctimas de la mutilación genital femenina."

${ }^{30} \mathrm{El}$ objeto de este protocolo es, de acuerdo con el CEDAW "establecer pautas de prevención y actuación contra la violencia de género que se ejerza sobre mujeres, beneficiarias de la red pública de centros de migraciones, por parte de quienes sean o hayan sido sus cónyuges o de quienes estén o hayan estado ligados a ellas por relaciones similares de afectividad, aún sin convivencia. Se tratará de impulsar también el establecimiento de medidas para prevenir, concienciar, detectar, proteger y asistir a las víctimas de acoso sexual y violencia por motivos de género, a sus hijos menores y a los menores sujetos a su tutela, o guarda y custodia. En la actualidad se está elaborando el borrador del Protocolo y se ha iniciado una experiencia piloto en el CAR de Vallecas" Comité para la Eliminación de la Discriminación contra la Mujer (2014)
}

\section{Conclusiones}

La VSBG se presenta como una pandemia de escala global y como uno de los principales desafíos para la consecución del pleno y universal reconocimiento de los derechos humanos.

Los alarmantes índices de VSBG en todas las regiones del mundo, y en particular en América Latina, revelan no solo la necesidad de partir de un enfoque preventivo, integral y ecológico que nos permita profundizar en la multicausalidad de éste fenómeno e identificar los principales actores y elementos que intervienen, tanto a nivel individual, familiar, social como institucional, sino también en la necesidad de fomentar la cooperación interestatal para el reconocimiento en la agenda de la comunidad global de un desafío estructural que transciende de la esfera privada a la pública y de la nacional a la internacional.

A pesar del anacronismo y del tradicional anclaje a los esquemas patriarcales de las normas internacionales reguladoras del derecho a solicitar protección internacional, así como del limitado reconocimiento de la VSBG en el seno de la agenda internacional hasta hace escasos años, desde una óptica iusinternacionalista puede apreciarse como los sistemas internacional y regionales de derechos humanos han venido estableciendo toda una serie de obligaciones jurídicas a los Estados relativas a la prevención, la erradicación y la protección frente a la VSBG.

A tal efecto, y a la luz de los avances analizados en el marco del denominado Derecho Internacional de los Refugiados, en gran parte debidos a la valiosa labor del Alto Comisionado de las Naciones Unidas para los Refugiados, tanto la normativa internacional, así como la regional en América Latina como en la Unión Europea, han ido reconociendo la legitimidad de la solicitud de la protección internacional para aquellas personas perseguidas por violencia sexual y por aquella basada en el género, inclusiva esta última de las persecuciones perpetradas por la orientación sexual o la identidad de género de la víctima/superviviente.

En el presente artículo, tras el estudio realizado desde el enfoque de género de los datos de las solicitudes de protección internacional presentadas en la UE, y en España, puede deducirse el mayor protagonismo en el proceso de asilo de los hombres frente al de las mujeres solicitantes de asilo debido principalmente, partiendo de la interseccionalidad que requiere la temática, a las múltiples barreras económicas, sociales, jurídicas, culturales y religiosas que dificulta el 
acceso a las mujeres a los procesos migratorios y de asilo.

Por su parte, del análisis realizado de la política de asilo de la UE, destacando los notables progresos y avances que se introducen en su normativa reguladora en cuestiones vinculadas al género, puede afirmarse que la política de asilo de la Unión continua operando desde un enfoque androcéntrico, nacionalista y jerárquico que no solo adolece de una profunda falta de voluntad política de cooperación y de fomento de la solidaridad entre los Estados miembros, sino que, además, posiciona a las personas perseguidas por motivos de género en una clara consideración de refugiados de segunda en relación con las personas perseguidas por los clásicos motivos del art.1.A.2) de la Convención de Ginebra de 1951.

A este respecto, destacan los desafíos, tanto a nivel teórico como práctico en el procedimiento de asilo, que el reconocimiento del género como causa de persecución presenta al no ser regulado como causa que opere de forma autónomo, sino articulado en relación con el motivo de pertenencia a un grupo social determinado y siempre en función de las circunstancias imperantes en el pais de origen.

Además, no resulta suficiente el reconocimiento del género como causa de persecución que legitime el posterior reconocimiento de la protección internacional. La necesaria generización de todo el engranaje del proceso de asilo pone de manifiesto el hecho de que las mujeres y las personas LGBT+ refugiadas, con independencia de si su estatuto de persona refugiada o la protección subsidiaria sean reconocidos por motivos de género o por otro de los motivos previstos en el art. 1.A2) de la Convención de Ginebra, pueden sufrir vulneraciones múltiples de sus derechos fundamentales a lo largo de todo el proceso de asilo.

A tal efecto, se ha destacado la necesidad de desarrollar mecanismos de identificación temprana de tales personas y de establecer una serie de garantías procesales en las entrevistas y en relación con la formación específica del personal que participa en las diferentes fases del proceso de asilo, con el objeto de garantizar que este último se articule desde el reconocimiento de la vulnerabilidad múltiple de las mujeres y personas LGBT+.

Finalmente, el estudio del Sistema Europeo Común de Asilo realizado desde una perspectiva de género, ha revelado como la consideración de los denominados países seguros, las condiciones de acogida y de recepción de las personas solicitantes, así como las cuestiones procesales relativas a la prueba deben ser objeto de una necesaria revisión y posterior análisis crítico para evitar la victimización secundaria de las mujeres y personas LGBT+, la vulneración del principio de non-refoulement y, fundamentalmente, para poder construir un marco garantista, efectivo, igualitario y común de protección internacional.

\section{Referencias}

Agencia de los Derechos Fundamentales de la Unión Europea (2014). Violence against women: an euwide survey. main results report. Technical report.

Alto Comisionado de las Naciones Unidas para los Derechos Humanos (2002). Leyes y prácticas discriminatorias y actos de violencia cometidos contra personas por su orientación sexual e identidad de género. Technical report, Alto Comisionado de las Naciones Unidas para los Derechos Humanos.

Alto Comisionado de las Naciones Unidas para los Refugiados (2002). Directrices sobre la protección internacional: "pertenencia a un determinado grupo social" en el contexto del Artículo 1.A.2) de la Convención de 1951 sobre el Estatuto de los Refugiados y/o su Protocolo de 1967. Technical report, Alto Comisionado de las Naciones Unidas para los Refugiados.

Alto Comisionado de las Naciones Unidas para los Refugiados (2003). Violencia sexual y por motivos de género en contra de personas refugiadas, retornadas y desplazadas internas. guía para la prevención y respuesta. Technical report, Alto Comisionado de las Naciones Unidas para los Refugiados.

Alto Comisionado de las Naciones Unidas para los Refugiados (2008). Nota de orientación del ACNUR sobre las solicitudes de la condición de refugiado relacionadas con la orientación sexual y la identidad de género. Sección de Políticas de Protección y Asesoría Legal. Dirección de Servicios de Protección Internacional. Technical report, Alto Comisionado de las Naciones Unidas para los Refugiados.

Alto Comisionado de las Naciones Unidas para los Refugiados (2012). Directrices sobre la protección internacional №9: Solicitudes de la condición de refugiado relacionadas con la orientación sexual y/o la identidad de género en el contexto del artículo 1A (2) de la Convención sobre el Estatuto de los Refugiados de 1951 y. Technical report, Alto 
Comisionado de las Naciones Unidas para los Refugiados.

Ankenbrand, B. (2002). Refugee women under german asylum law. International Journal of Refugee Law, 14(1).

Brysk, A. (2017). Introducción: violencia de género y relaciones internacionales. Revista CIDOB d'Afers Internacionals, (117):7-28.

Caloz-Tschopp, M. C. (1997). La création de la démocratie et de l'asile par l'action contre le néo-libéralisme sécuritaire.

Charlesworth, H., Chinkin, C., y WRight, S. (1992). Feminist approaches to international law. The American Journal of International Law, 85(4).

Comisión Española de Ayuda al Refugiado (2018). Comisión Española de Ayuda al Refugiado.

Comité para la Eliminación de la Discriminación contra la Mujer (2014). Recomendación general núm. 32 sobre las dimensiones de género del estatuto de refugiada, el asilo, la nacionalidad y la apatridia de las mujeres. CEDAW/C/GC/32. Technical report, Comité para la Eliminación de la Discriminación contra la Mujer.

Consejo de Seguridad de las Naciones Unidas (2000). Resolución 1325 (2000) aprobada por el consejo de seguridad en su sesión 4213.

Díaz Lafuente, J. (2016). Asilo y refugio por motivos de orientación sexual e identidad de género. Congreso de los Diputados.

Goodwin-Gill, G. S. (1986). Non-Refoluement and the New Aylum Seekers. Virginia Journal of International Law, 897.

Goodwin-Gill, G. S. y McAdam, J. (2007). The refugee in international law. Oxford University Press, Nueva York.

Hathaway, J. C. (1991). The law of refugee status, volumen 104. Butterworths Toronto, Toronto.

Heise, L. (1998). Violence against women: an integrated, ecological framework. Violence Against Women, 3:262-290.

Jiménez Sánchez, C. (2017). La persecución de género en el Derecho Internacional de los Refugiados: Nuevas perspectivas. Revista Electrónica de Estudios Internacionales (REEI), (33):5.
Jordan, S., Bahreini, R., y Lidstone, R. (2012). LGBT (Lesbian, Gay, Bisexual, Transgender) Refugees and Sexual Orientation / Gender Identity Asylum: An Annotated Bibliography of Selected Legal and Social Scientific Publications.

Kneebone, S. (2005). Women within the refugee construct: 'exclusionary inclusion' in policy and practice - the australian experience. International Journal of Refugee Law, 17(1).

Krug, G., Dahlberg, L., Mercy, J., Zwi, A., y Lozano, R. (2002). World report on violence and health. Organización Mundial de la Salud, Ginebra.

Lagarde, M. (2006). Del Femicidio al Feminicidio. Revista de Psicoanálisis, (6):216-225.

Lentini, E. (1985). The Definition of Refugee in International Law: Proposals for the future. Boston Call, Third World.

López Pons, M. M. (2011). La Violencia de Género en el Territorio Latinoamericano, a través de la Ocurrencia Creciente de los Feminicidios en la Región. Revista Latino-Americana de Geografia e Gênero, 1(1):78-88.

Mahamut, R. G. (2016). La ductilidad del derecho a la protección internacional (refugio y protección subsidiaria) ante las crisis humanitarias: un desafío para Europa y para el sistema europeo común de asilo. Teoría y realidad constitucional, (38):211238.

Ministerio del Interior y Gobierno de España (2017). Asilo en cifras. 2016.

Oficina de las Naciones Unidas contra la Droga y el Delito (2014). El asesinato de mujeres y niñas por razones de género: prácticas prometedoras, dificultades y recomendaciones concretas. UNODC/CCPCJ/EG.8/2014/2. Technical report, Oficina de las Naciones Unidas contra la Droga y el Delito.

Organización Internacional del Trabajo (2017). Global estimates of modern slavery: Forced labour and forced marriage. Technical report, Organización Internacional del Trabajo.

Organización Mundial de la Salud (2013). Estimaciones mundiales y regionales de la violencia contra la mujer: Prevalencia y efectos de la violencia conyugal y de la violencia sexual no conyugal en la salud. Technical report, Organización Mundial de la Salud.

Rev. Est. de Políticas Públicas, 2018, 8(noviembre) 
Parlamento Europeo (2011). Directiva 2011/95/ue por la que se establecen normas relativas a los requisitos para el reconocimiento de nacionales de terceros países o apátridas como beneficiarios de protección internacional, a un estatuto uniforme para los refugiados o para las personas con derecho a protección subsidiaria y al contenido de la protección concedida.

Parlamento Europeo (2012). Resolución de 24 de mayo de 2012 , sobre la lucha contra la homofobia en europa.

Programa de Naciones Unidas para el Desarrollo (2017). Del Compromiso a la Acción: Políticas para Erradicar la Violencia contra las Mujeres América Latina y el Caribe. Technical report, Programa de Naciones Unidas para el Desarrollo.

Saccomano, C. (2017). El feminicidio en América Latina: ¿Vacío legal o déficit del Estado de derecho? Revista CIDOB d'Afers Internacionals, (117):5178 .

Trujillo Herrera, R. (2003). La Unión Europea y el derecho de asilo. Dykinson, Madrid.

Unión Europea y Agencia Eurostat (2018). Asylum statistics.

Unión Europea y Parlamento Europeo (2016). Gender aspects of migration and asylum in the EU: An overview.

Wijnkoop, M. y Vloeberghs, E. (2010). Traumatized asylum seekers: A vulnerable group asylum seekers with special needs in the asylum process. En $M i$ nisterial Conference "Quality and Efficiency in the Asylum Process", Bruselas.

Rev. Est. de Políticas Públicas, 2018, 8(noviembre) 